\title{
Out-of-sequence thrusting in Himalaya: Modification of wedge extrusion and channel flow models
}

\author{
CS Dubey ${ }^{*}$, BK Sharma†, EJ Catlosł and RA Marston $\ddagger$ \\ † Department of Geology, University of Delhi, Delhi-110 007, INDIA \\ ¥ School of Geology, Oklahoma State University, Stillwater, Oklahoma, USA \\ *Towhom correspondence should be addressed.Email:csdubey@yahoo.com
}

Recent seismic events in the Lesser Himalayas between the Main Central Thrust (MCT) and Main Boundary Thrust (MBT) have brought to light the importance of paleoslip along structures in controlling mass movement in the area, as evidenced by several devastating landslides and major earthquake in 1991. In Uttarkashi region MCT shear zone can be divided into three different thrusts i.e. MCT-I (Vaikrita thrust), MCT-II (Munsiari/ Jutogh Thrust), MCT-III (Chail/Ramgarh Thrust). The rocks present between Munsiari Thrust in Bhatwari area and Ramgarh/ Chail thrust near Sainj (Garhwal Himalaya) depict very young in situ monazites ages varying from 6-1 Ma (Catlos et al. 2003). The younger ages and the geometry of the MCT-III reveal this thrust to be an out-of-sequence thrust reactivating the MCT-II, i.e., the MunsiariThrust.

Schelling and Arita (1991) and Pandey andVirdi (2004) have also observed such relationships in Nepal and Himachal Pradesh respectively. MCT-III is a high angle reverse thrust fault at Sainj and it extends in the Sarhan-Jhakri area (Himachal Pradesh) where monazite dates obtained are as young as 3.4 Ma. This Thrust is also observed as high angle reverse Fault at Pachekhani mines, Rorathang and Ranpo in Sikkim. These relationships may have implications on the high seismic activity in the Himalaya at regional scale between MCT-I (Vaikrita thrust) and MBT due to an out of sequence thrust reactivating older thrusts in the hinterland affecting the break in slope, probably affecting the climate change as reflected in the stable isotopes from the Lesser Himalaya (Hodges et al. 2004). Occurrences of such out-ofsequence thrusts have been known (at several other locations near the STD, MCT-I and MCT-III and above MBT (Grujic et al. 2002; Catlos et al. 2003). Out-of-Sequence thrusts and related Neotectonic activity clearly depicts that the channel flow model and wedge extrusion models need modifications in the light of above. A modified model based on the data from the Lesser Himalayan region from East to West will be discussed.

\section{References}

Catlos EJ, CS Dubey, RA Marston and TM Harisson. 2003. Moving mountains: Reactivation of the Himalayan Main Central Thrust at 4 Ma Bhagirathi river, NW India. Geol Soc Am Paper \# 60243, Seatle meeting, USA

Grujic D, LS Hollister and RR Parrish. 2002. Himalayan metamorphic sequence as an orogenic channel: insight from Bhutan. Earth Planet Sci Lett, 198; 177-191

Pandey AK, HK Sachan and NS Virdi. 2004 Exhumation history of a shear zone constrained by Microstructural and fluid inclusion techniques: an example from the Satluj valley, NW Himalaya, India, Jour Asian Earth Sc 23: 391-406

Schelling D and K Arita. 1991. Thrust tectonics, crustal shortening, and the structure of the far-eastern Nepal Himalayas. Tectonics 10: 851-862

Hodges KV, CWobus, K Ruhl, T Schildgen and KWhipple. 2004. Quaternary deformation, river steepening, and heavy precipitation at the front of the Higher Himalayan ranges. Earth Planet Sci Lett 220: 379-389 